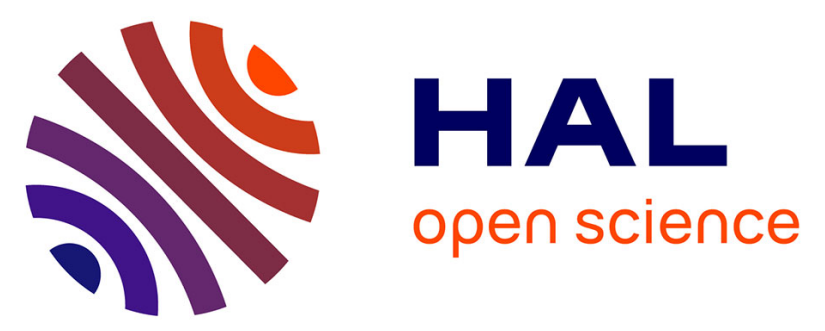

\title{
Investigation on chip formation and surface morphology in orthogonal machining of Zr-based bulk metallic glass
}

Karuna Dhale, Nilanjan Banerjee, Ramesh Kumar Singh, José Outeiro

\section{To cite this version:}

Karuna Dhale, Nilanjan Banerjee, Ramesh Kumar Singh, José Outeiro. Investigation on chip formation and surface morphology in orthogonal machining of Zr-based bulk metallic glass. Manufacturing Letters, 2019, 19, pp.25-28. 10.1016/j.mfglet.2019.01.002 . hal-02502739

\section{HAL Id: hal-02502739 \\ https://hal.science/hal-02502739}

Submitted on 12 Mar 2020

HAL is a multi-disciplinary open access archive for the deposit and dissemination of scientific research documents, whether they are published or not. The documents may come from teaching and research institutions in France or abroad, or from public or private research centers.
L'archive ouverte pluridisciplinaire $\mathbf{H A L}$, est destinée au dépôt et à la diffusion de documents scientifiques de niveau recherche, publiés ou non, émanant des établissements d'enseignement et de recherche français ou étrangers, des laboratoires publics ou privés. 


\section{Investigation on chip formation and surface morphology in orthogonal machining of Zr-based bulk metallic glass}

Abstract

Karuna Dhale ${ }^{\mathrm{a}}$, Nilanjan Banerjee ${ }^{\mathrm{b}}$, Ramesh KumarSingh ${ }^{\mathrm{b}}$, José Outeiro ${ }^{\mathrm{c}}$

This work presents the preliminary investigation on the orthogonal machining of Zr-based bulk metallic glass. Influence of machining parameters on the chip formation mechanisms has been analyzed. The SEM images of the chip surfaces have been taken for this purpose. It has been observed that at lower speed and uncut chip thickness, the individual serrated sections of chips develop shear bands in the surface. At higher speed and uncut chip thickness, these shear bands aggravate and leads to form fragmented surfaces. Degree of segmentation and serration spacing of chips were analyzed and compared with the morphology of the machined surface.

Keywords: Bulk metallic glass, Serrated chips, Shear bands, Degree of segmentation

\section{Introduction}

Metallic glasses are amorphous alloys with disordered structure at the atomic scale. In recent years, bulk metallic glasses (BMG) have been of great technological and scientific interest. Due to the absence of grain boundaries, they possess unique properties like high hardness, large elastic strain, ultra-high strength, excellent wear and corrosion resistance, compared to their crystalline counterparts [1]. Machining is an important process for manufacturing of BMG components with high dimensional accuracy. Due to very low thermal conductivity and high strength, the machining of BMG becomes difficult, as the heat generated is not dissipated [2]. During the machining of metallic alloys, under certain machining conditions, serrated chips were generated due to the formation of shear bands [3]. Since the chip morphology can influence the other machining outcomes like force fluctuation, surface integrity, tool life etc., hence its understanding is needed to achieve better machining performance. Although for the cases of crystalline alloys, several investigations on shear bands generated during chip formation are available, but in the case of BMGs (amorphous alloys), very limited work has been reported to understand its effect on chip formation mechanisms.

Over the years, very few investigations regarding the machining of BMG have been reported. Some of the specific observations associated with the chip formation of BMG include, chip light emissions, and oxidation and crystallisation of the chips $[4,5]$. Repeated shear bands in the primary shear zone were observed during chip formation of BMG, in the work of [6]. Very limited study on the effect of machining parameters on surface morphology and machinability studies were also mentioned in [7] and [8].

Although in the previous works, chip morphology was discussed, but a comprehensive investigation regarding the shear band evolution during the chip formation process for bulk metallic glass is clearly absent. Furthermore, lack of clear understanding regarding the deformation behaviour of BMG also makes this area worth to explore.

Hence, the primary goal of this work is to understand the shear band evolution during chip formation of BMGs at very low cutting speeds and uncut chip thickness. The chip morphology, degree of segmentation, serration spacing and surface morphology has been investigated on Zr-based BMG.

a - Centre for Research in Nanotechnology and Science, Indian Institute of Technology Bombay, Mumbai 400076, India

b-Department of Mechanical Engineering, Indian Institute of Technology Bombay, Mumbai 400076, India

c- LaBoMaP, Arts et Métiers Paristech Cluny, Rue porte de Paris, Cluny 71250, France 


\section{Experimental Details}

Orthogonal cutting experiments were conducted on $\mathrm{Zr}$-based BMG $\left(\mathrm{Zr}_{67} \mathrm{Cu}_{10.6} \mathrm{Ni}_{9.8} \mathrm{Ti}_{8.8} \mathrm{Be}_{3.8}\right.$ (wt\%), commonly known as Vit $1 \mathrm{~b}-\mathrm{X}$. The material was in the form of a rectangular plate of $0.8 \mathrm{~mm}$ in thickness. The material properties of the workpiece as well as the experimental set up are shown in the Fig. 1 . The experiments were performed on a high precision CNC machining center (MikroTools DT 110i) using PVD coated ( $\mathrm{Ti}, \mathrm{Al}) \mathrm{N}$ carbide inserts. The edge width of the cutting insert was $3.18 \mathrm{~mm}$ with $0^{\circ}$ rake angle. The edge radius was $15 \mu \mathrm{m}$ and the clearance angle was $10^{\circ}$. The tests were carried out at five different cutting speeds $0.1 \mathrm{~m} / \mathrm{min}, 0.5 \mathrm{~m} / \mathrm{min}, 1.0 \mathrm{~m} / \mathrm{min}, 1.5 \mathrm{~m} / \mathrm{min}$ and $2.0 \mathrm{~m} / \mathrm{min}$ and three uncut chip thickness of $20 \mu \mathrm{m}, 30 \mu \mathrm{m}$ and $40 \mu \mathrm{m}$. All the tests were performed under dry cutting conditions. The chips collected were cleaned thoroughly by ultrasonication and were then observed under Hitachi Scanning Electron microscope (SEM). The surface roughness measurement and optical images of the machined surface was taken using a profilometer (Alicona infinite focus).

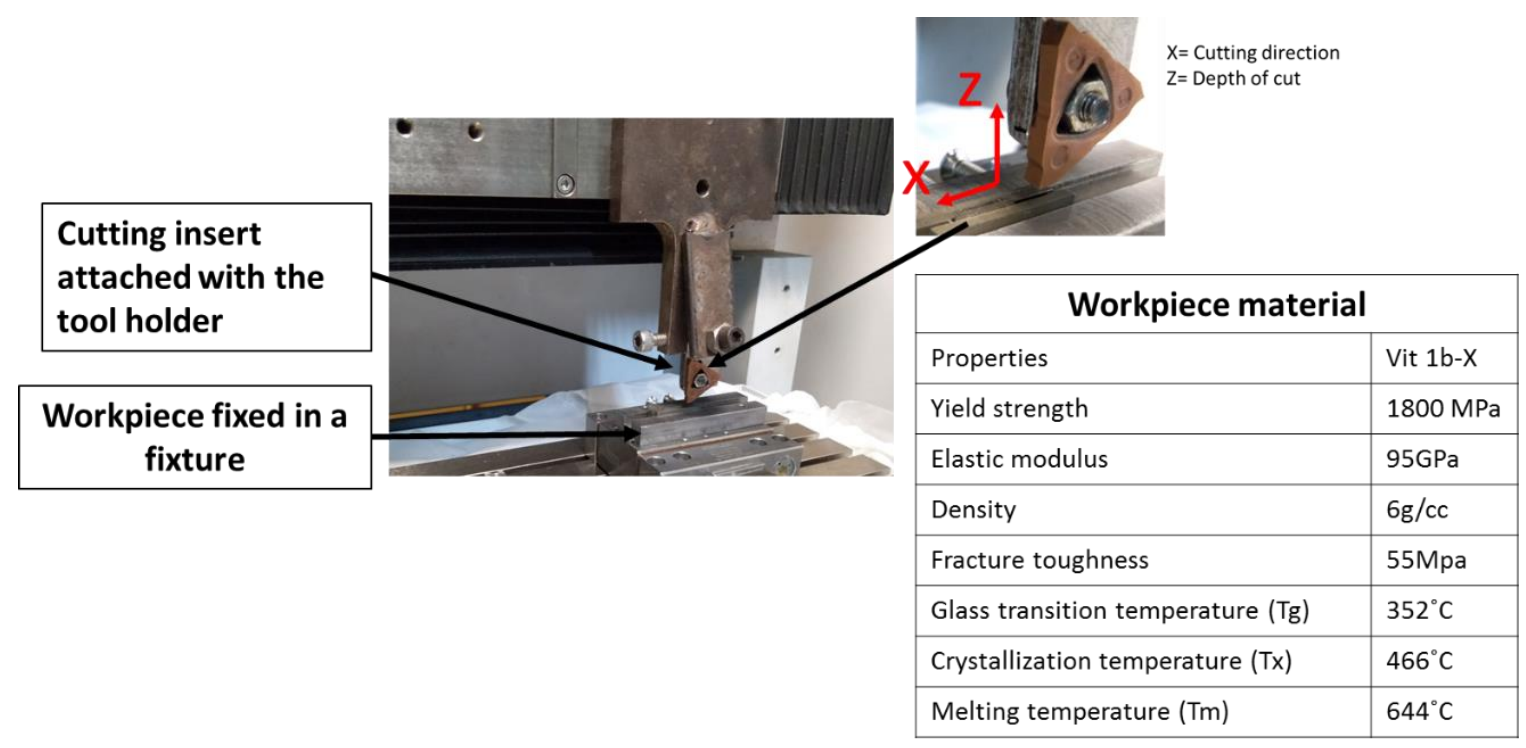

Fig. 1: Experimental set up

\section{Result and Discussion}

\subsection{Chip morphology}

The chip morphology obtained in the case of BMG seems to be quite different from those seen in crystalline alloys, especially the presence of secondary shear bands [Fig. 2] [6]. It can be seen that the serrated chips are formed under all the conditions of cutting speed and uncut chip thickness. At an uncut chip thickness of $20 \mu \mathrm{m}$, very thin serrated structures can be observed at all the cutting speeds investigated. As the cutting speed is increased from $0.1 \mathrm{~m} / \mathrm{min}$ to $1.0 \mathrm{~m} / \mathrm{min}$, secondary shear bands emerges within each serrated section, suggesting the onset of severe narrow localized plastic deformation within the individual serrated section. With a further increase in the cutting speed to 2.0 $\mathrm{m} / \mathrm{min}$, because of the increase in the strain rate, these shear bands get aggravated throughout the individual serrated region of the chip. 


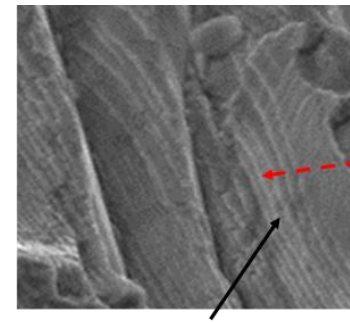

Secondary shear bands in individual serrated section

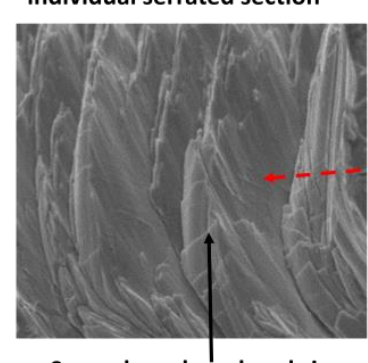

Secondary shear bands in individual serrated section

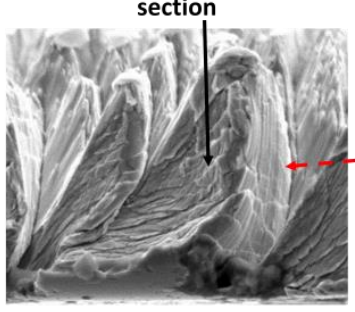

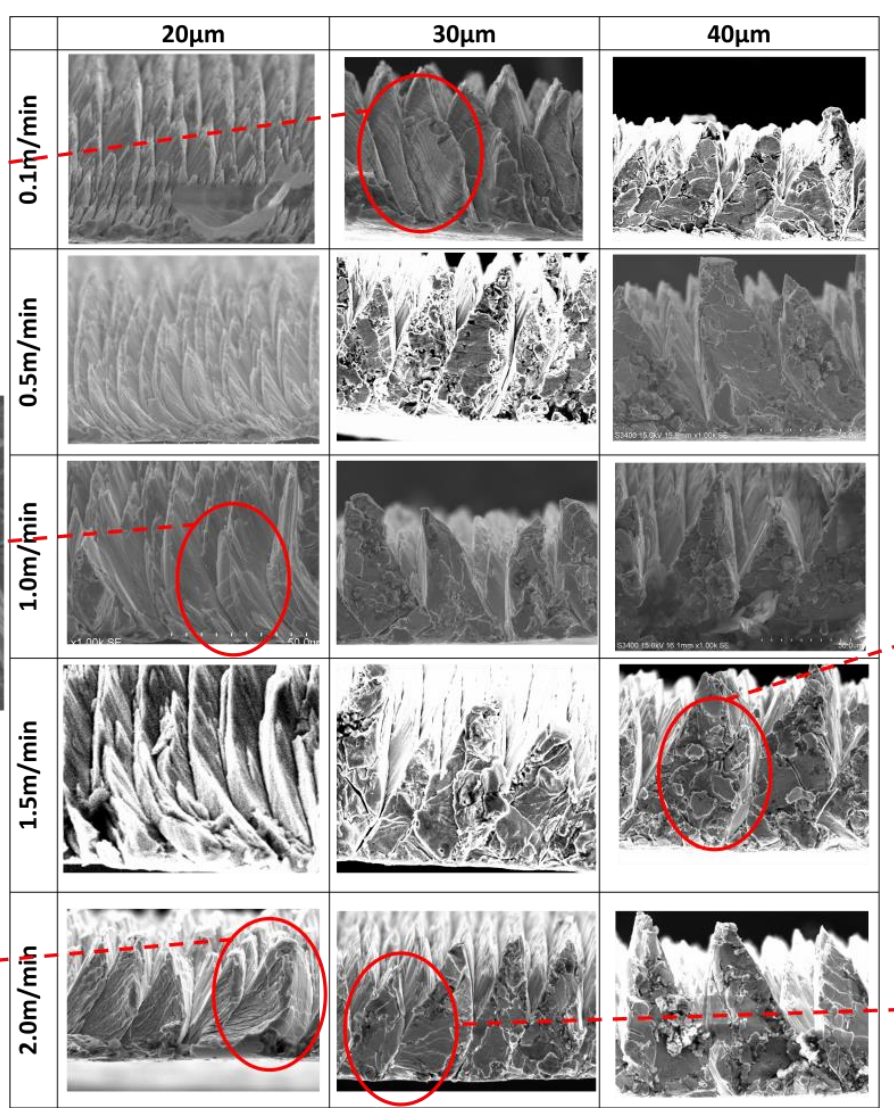

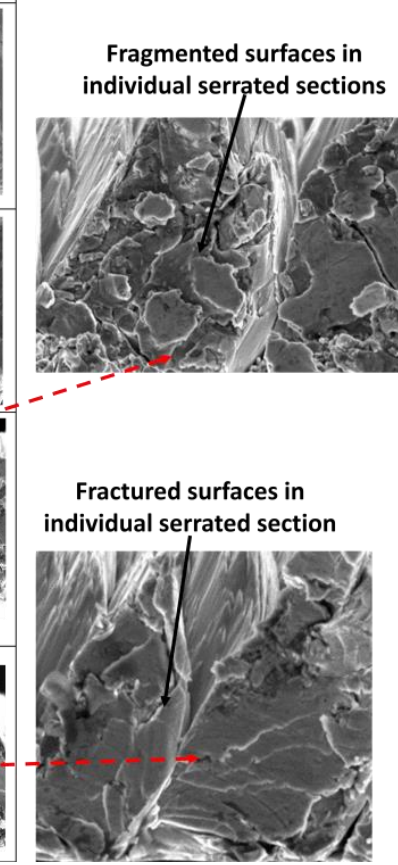

Fig. 2: SEM images of the chip morphology obtained at different cutting speed and uncut chip thickness (Magnification: 1.00KX).

At $30 \mu \mathrm{m}$ uncut chip thickness, the secondary shear bands in the individual serrated region are visible at a cutting speed of $0.1 \mathrm{~m} / \mathrm{min}$. The shear bands observed are parallel to each other and do not intersect. With a further increase in the cutting speed from $0.5 \mathrm{~m} / \mathrm{min}$ to $2.0 \mathrm{~m} / \mathrm{min}$, the shear bands grow rapidly and propagate within the chip because of intense plastic deformation resulting in the formation of fractured surfaces. In the case of $40 \mu \mathrm{m}$ chip thickness, the fragmented surfaces within individual serrated sections are visible at the cutting speed of $0.1 \mathrm{~m} / \mathrm{min}$. An increase in the cutting speed has a profound effect on fragmented surfaces. A high strain in the individual serrated region is induced due to severe plastic deformation which increases the degree of fragmentation observed in the chip, specifically from $1.0 \mathrm{~m} / \mathrm{min}$ to $2.0 \mathrm{~m} / \mathrm{min}$. It can be seen that the secondary shear band formation initiates from the high strain region and moves towards the low strain region. The fracture surfaces are mostly accumulated towards the low strain region and the fracture phenomenon seems to be of brittle nature, when compared with crystalline metallic alloys. This kind of serration and fracture pattern suggests that the chip formation mechanism in the BMG is governed by both brittle and ductile kinds of fracture [9]. It should also be noted that the shear band formation and propagation within the individual serrated structure is not seen generally in the chips obtained from machining of crystalline alloys [6], although in some cases slip lines and mechanical twins are observed [11]. 


\subsection{Effect on Degree of segmentation (Ds) and serration spacing}

The degree of segmentation is an important measure of the chip formation mechanism in metal alloys which exhibit shear band and crack formation [10]. A linear increase in the degree of segmentation is observed with an increase in the cutting speed from $0.1 \mathrm{~m} / \mathrm{min}$ to $1.0 \mathrm{~m} / \mathrm{min}$ and then a sudden drop occurs at $1.5 \mathrm{~m} / \mathrm{min}$ as seen in Fig $3(\mathrm{a})$. It seems that the linear increase from $0.1 \mathrm{~m} / \mathrm{min}$ to $1.000 \mathrm{~m} / \mathrm{min}$ is due to the aggressive shear band formation and the sudden drop from $1.5 \mathrm{~m} / \mathrm{min}$ could be attributed to the initiation of fracture inside the shear bands of the individual serrated chip which resulted in the decrease of peak height of the segmented region.

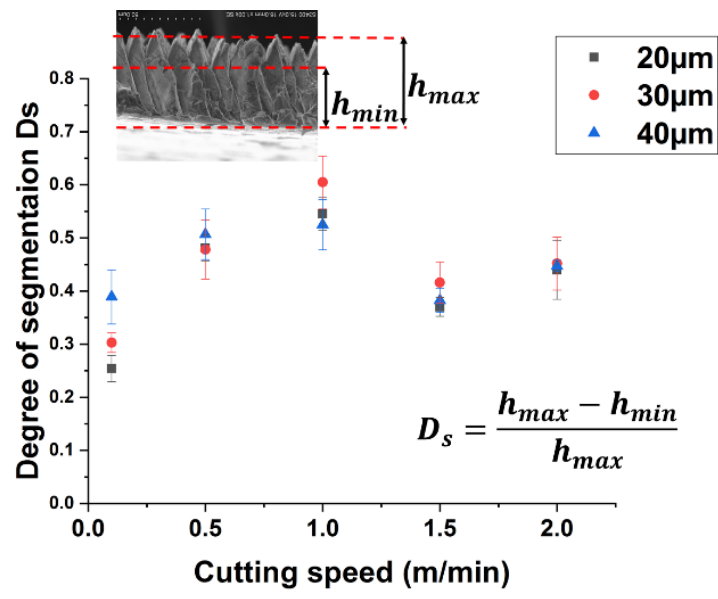

(a)

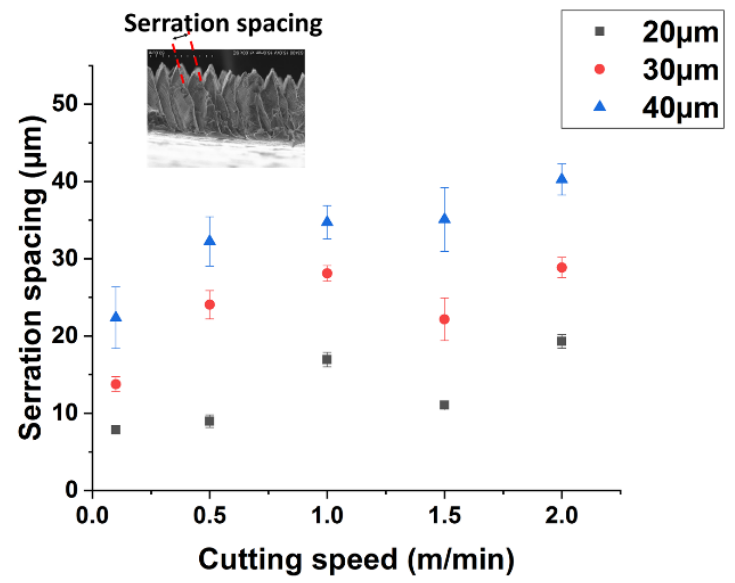

(b)

Fig. 3: Effect of machining parameters on (a) Degree of segmentation (b) Serration spacing

The serration spacing increases with the cutting speed and at all uncut chip thicknesses as shown in Fig. 3(b). Under the conditions investigated, the highest values for serration spacing is at an uncut chip thickness of $40 \mu \mathrm{m}$ whereas the lowest values for serration spacing is found at an uncut chip thickness of $20 \mu \mathrm{m}$. At lower cutting speeds, due to low shear strains in the material, more shear bands are generated. Hence, the serrations are closely placed as well as larger in numbers as shown in Fig.2. At higher cutting speeds, due to the severe deformation (high shear strain) of the material and the propagation of shear bands results in fractured surfaces within the individual serrated sections. This leads to an increase in the spacing between the two individual consecutive serrated sections.

\subsection{Effect on surface morphology}

The different type of chip formations can significantly influence the 3-D average surface roughness $\left(S_{a}\right)$ of the machined surface as seen in Fig.4. A higher surface roughness value of $2.6 \mu \mathrm{m}$ was obtained at a cutting speed of $1.0 \mathrm{~m} / \mathrm{min}$ and an uncut chip thickness of $40 \mu \mathrm{m}$ whereas the surface roughness of 1.3 $\mu \mathrm{m}$ was obtained at a speed of $1.5 \mathrm{~m} / \mathrm{min}$ and an uncut chip thickness of $30 \mu \mathrm{m}$. The variation in the degree of segmentation can also influence the surface roughness. It can be observed from the Fig.3 (a) and Fig. 4 that the degree of segmentation is closely correlated with surface roughness over the entire speed range of $0.1 \mathrm{~m} / \mathrm{min}$ to $2.0 \mathrm{~m} / \mathrm{min}$. As discussed in the previous section, fractured sections in the chips are produced at higher cutting speeds and larger uncut chip thickness result in a higher roughness at $1.0 \mathrm{~m} / \mathrm{min}$. Due to the presence of brittle fracture mode and tearing of the material at this condition, tiny craters are generated on the machined surface which deteriorates the surface finish. The improved 
surface finish at $1.5 \mathrm{~m} / \mathrm{min}$ and uncut chip thickness of $30 \mu \mathrm{m}$ may be attributed to the lower degree of chip segmentation.

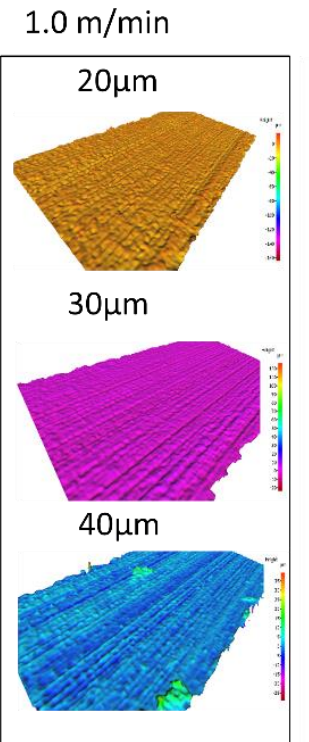

Magnification: 10x

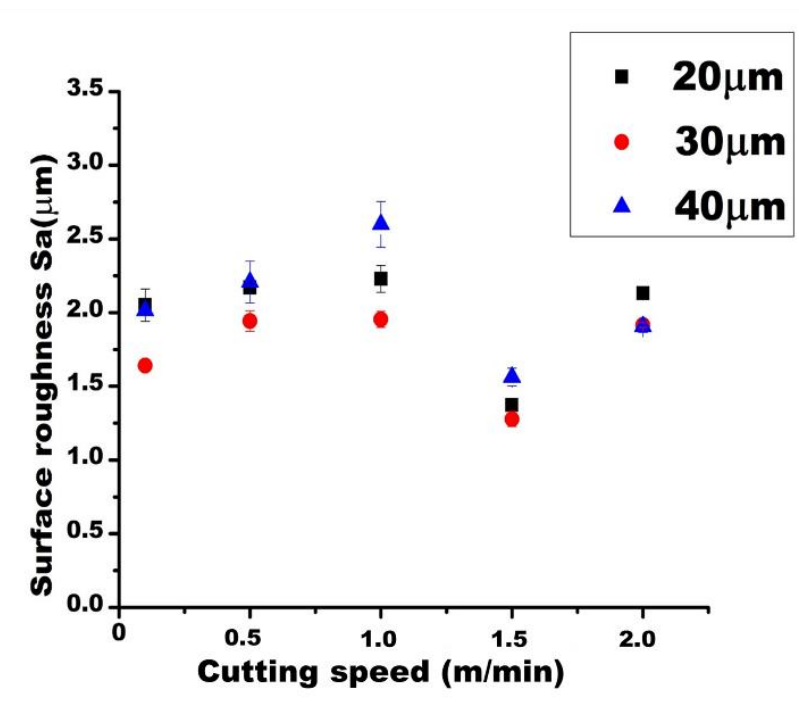

Cutting speed (m/min)
$1.5 \mathrm{~m} / \mathrm{min}$

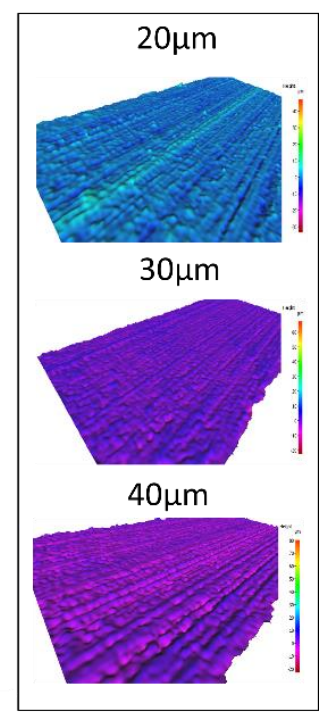

Magnification: 10x

Fig. 4: Effect of change in cutting speed and uncut chip thickness on surface roughness (Sa).

This work can be further extended to understand the effect of machining parameters on other surface integrity characteristics like surface and sub-surface hardness variation, residual stress, crystallization of the machined surface, surface waviness pattern etc., which can give a broader picture about the machining performance.

\section{Conclusion}

This paper is focused on understanding the chip formation mechanism in low-speed orthogonal machining of Zr-based BMG. Following specific conclusions can be drawn from this work:

1. Shear bands are generated at the individual serrated region of the chips at low cutting speeds.

2. At higher cutting speeds $(>1.0 \mathrm{~m} / \mathrm{min})$, fracture and fragmentation at the individual serrated region is observed due to the propagation of shear bands.

3. The degree of segmentation increases linearly from $0.1 \mathrm{~m} / \mathrm{min}$ to $1.0 \mathrm{~m} / \mathrm{min}$ due to the aggressive shear band formation and then suddenly drop at $1.5 \mathrm{~m} / \mathrm{min}$ possibly due to the reduced severity of segmentation and the initiation of fracture inside the shear bands. The serration spacing increases with an increase in the cutting speed and uncut chip thickness.

Surface roughness is influenced by the degree of segmentation and the lowest surface roughness is obtained for the cutting speed of $1.5 \mathrm{~m} / \mathrm{min}$.

\section{References}

[1] Wang WH, Dong C, Shek CH. Bulk metallic glasses. Mater. Sci. Eng. R Rep 2004 Jun 1; 44(2-3):4589. https://doi.org/10.1016/j.mser.2004.03.001. 
[2] Yavari AR, Lewandowski JJ, Eckert J. Mechanical properties of bulk metallic glasses. MRS Bull 2007 Aug; 32(8):635-8. https://doi.org/10.1557/mrs2007.125

[3] Dinakar Sagapuram, Koushik Viswanathan. Viscous shear banding in cutting of metals. J Manuf Sci Eng 2018; 140(11):111004-7.https://doi 10.1115/1.4040875.

[4] Bakkal M, Shih AJ, Scattergood RO. Chip formation, cutting forces, and tool wear in turning of Zrbased bulk metallic glass. Int J Mach Tool Manu 2004 Jul 1; 44(9):915-25. https:// doi:10.1016/j.ijmachtools.2004.02.2002.

[5] Bakkal M, Liu CT, Watkins TR, Scattergood RO, Shih AJ. Oxidation and crystallization of Zr-based bulk metallic glass due to machining. Intermetallics 2004 Feb 1; 12(2):195-204. https://doi:10.1016/i.intermet.2003.09.017.

[6] Jiang MQ, Dai LH. Formation mechanism of lamellar chips during machining of bulk metallic glass. Acta Mater 2009 May 1; 57(9):2730-8. https://doi.org/10.1016/j.actamat.2009.02.031.

[7] Han DX, Wang G, Li J, Chan KC, To S, Wu FF, Gao YL, Zhai QJ. Cutting characteristics of Zr-based bulk metallic glass. J Mater Sci Technol 2015 Feb 1; 31(2):153-8. https://dx.doi.org/10.1016/j.jmst.2014.11.010.

[8] Fujita K, Morishita $\mathrm{Y}$, Nishiyama N, Kimura H, Inoue A. Cutting characteristics of bulk metallic glass. Mater Trans. 2005; 46(12): 2856-63. https://doi.org/10.230/matertrans.46.2856.

[9] Zeng F, Jiang MQ, Dai LH. Dilatancy induced ductile-brittle transition of shear band in metallic glasses. $\quad P$ Roy Soc A-Math Phy 2018 Apr 11; 474(2212):20170836. https://doi.org/10.1098/rspa.2017.0836.

[10] Özel T, Ulutan D. Effects of machining parameters and tool geometry on serrated chip formation, specific forces and energies in orthogonal cutting of nickel-based super alloy Inconel 100. Proc. Inst. Mech. Eng. B 2014 Jul; 228(7): 673-86. https:// doi.org/10.1177/0954405413510291.

[11] M'Saoubi R, Ryde L. Application of the EBSD technique for the characterisation of deformation zones in metal cutting. Mater. Sci. Eng. C 2005 Sep 25; 405(1-2):339-49. https://doi.org/10.1016/j.msea.2005.06.002. 